\title{
Research on the Relationship between Iron Ore Futures Price and Spot Price in China
}

\author{
Hui Sheng \\ School of Finance \\ Guizhou University of Finance and Economics \\ Guiyang, China \\ 1206424342@qq.com
}

\begin{abstract}
Based on cointegration test, vector error correction model and impulse response function, this paper took the relevant daily data from October 2013 to May 2018 as the research object to study the relationship between iron ore futures price and spot price in China. The results show that there is a long-term equilibrium relationship between iron ore futures price and spot price. Compared with the futures market, the spot market is more sensitive to the departure of short-term price from equilibrium, and adjusts long-term equilibrium more quickly. The spot price unidirectionally guides the futures price. The impact strength of the futures market on the spot market is higher than that of the spot market on the futures market.
\end{abstract}

Keywords-Iron ore futures price; Iron ore spot price; Cointegration test; Vector error correction model; Impulse response

\section{INTRODUCTION}

With the rapid development of economic society, the "financialisation" of bulk commodities has become an inevitable trend. As some international organizations tried to promote iron ore index pricing mechanism, the iron ore long-term agreement mechanism, which had lasted for 40 years, was finally dead and buried in 2010. China is the world's largest iron ore consumer and its reliance on imported iron ore has dictated that China has little voice in iron ore pricing. In order not to be controlled by the price that other countries set, China launched iron ore futures in Dalian Commodity Exchange in 2013. Since then, iron ore futures has played an important role in China's futures markets. In 2017, the iron ore futures market in Dalian Commodity Exchange realized bilateral trading volume of 660 million lots, nearly 2.6 million lots which is the equivalent of 2.6 million tons of iron ore a day, and it became the largest iron ore financial derivative. In 2018, China's iron ore futures markets introduced foreign traders business, which will further enhance the influence of China's futures. After the first step of internationalization of China's crude oil futures, the internationalization of China's iron ore futures has been gradually put on the agenda. Therefore, the research of the relationship between China's iron ore futures price and spot price will help to analyze the operational efficiency of the iron ore futures market, which can further promote the internationalization of China's iron ore futures.

\section{LITERATURE REVIEW}

A large number of literature abroad have discussed the relationship between futures markets and spot markets. Engle and Granger (1987) proposed a cointegration analysis method to investigate the long-term stable relationship between time series with the same single integer order [1]. Subsequently, Lai et al. (1991) used cointegration theory to empirically examined the relationship between futures prices and spot prices [2]. Booth et al. (1999) researched stock index and index futures in German using DAX index securities based on cointegration analysis and error correction model, and the results showed that the futures market has the function of price discovery [3].

At present, domestic discussions on futures price and spot price mainly focus on the financial market, agricultural product market, metal material market and so on. For the financial market, Sun Xinxin (2018) believed that there is a strong linkage between the CSI 300 index futures and spot markets, which fluctuates greatly [4]. For the agricultural product market, Song Bo et al. (2018) found that there is cointegration and two-way transmission relationship between the futures and spot prices of corn and soybean in China, but the impact of the corn futures market is greater than that of the corn spot market, while the situation of soybeans is reversed; however, there is no long-term equilibrium relationship between the wheat futures and spot prices [5]. For the metal material market, Dong Shanshan et al. (2016) thought that both gold and silver futures markets work efficiently, however, the silver futures market has more contribution to price discovery than the gold futures market, while gold spot price has more leading power than gold futures price because the industrial demand for gold is lower than that for silver and the speculative atmosphere in the gold futures market is thicker than that in the silver futures market [6].

The academic circle has strong bases of the relationship between the futures price and the spot price, but researches on iron ore futures markets by domestic scholars are still at the exploratory stage. Therefore, this paper analyses the relationship between the iron ore futures price and spot price in China and puts forward some suggestions according to the operation of the iron ore futures market. 


\section{EMPIRICAL ANALYSIS}

\section{A. Sample selection}

In this paper, relevant intraday data from October 18, 2013 to May 16, 2018 are selected as the research sample. China's iron ore futures price is represented by the settlement price of the iron ore futures in Dalian Commodity Exchange because settlement price is the average futures price based on the weighted average of the trading volume of all iron ore transactions on that day, which can rule out price fluctuation caused by abnormal factors in the daytime and better reflect the results of trades. China's iron ore spot price is represented by China Iron Ore Price Index (CIOPI) that is composed of two parts: the domestic iron ore price index and the imported iron ore price index. All data are from Forward Looking Database.

Because the trading day of futures markets is not synchronized with the announcement date of spot price, it is necessary to pair these two sets of data. After removing the asynchronous data, 1030 groups of valid samples can be used in the study. In order to eliminate the heteroscedasticity, this study takes the natural logarithmthe of sample data, which means the futures price is represented by $\ln F$ and the spot price is represented by $\operatorname{lnP}$, while the corresponding first-order difference variables are represent by $d \ln F$ and $d \ln P$ respectively.

\section{B. Unit root test}

Use ADF test to examine iron ore futures and spot prices and the results are shown in Table 1 . Neither $\ln F$ nor $\ln P$ can reject the original hypothesis that there is a unit root, so both $\operatorname{lnF}$ and $\ln \mathrm{P}$ are nonstationary time series, but their first-order difference sequences $d \ln F$ and $d \ln P$ are stationary time series. Both $\mathrm{d} \ln \mathrm{F}$ and $\mathrm{d} \ln \mathrm{P}$ are first order single integer time series, that is, $\operatorname{lnF} \sim \mathrm{I}(1), \ln \mathrm{P} \sim \mathrm{I}(1)$.

TABLE I. ADF TEST

\begin{tabular}{|c|l|l|l|l|l|l|}
\hline Variable & t-Statistic & Prob. & $\mathbf{0 . 0 1}$ Critical Value & $\mathbf{0 . 0 5}$ Critical Value & 0.1 Critical Value & Stable or not \\
\hline LnF & -2.218494 & 0.4782 & -3.967009 & -3.414195 & -3.129207 & no \\
\hline $\mathbf{L n P}$ & -2.176151 & 0.5019 & -3.967009 & -3.414195 & -3.129207 & no \\
\hline $\mathbf{d}(\mathbf{l n F})$ & -21.50721 & 0.0000 & -3.967009 & -3.414195 & -3.129207 & yes \\
\hline $\mathbf{d}(\mathbf{l n P})$ & -20.88433 & 0.0000 & -3.967009 & -3.414195 & -3.129207 & yes \\
\hline
\end{tabular}

\section{Cointegration test}

$\mathrm{LnF}$ and $\mathrm{lnP}$ are the same order single integer time series, and there may be cointegration relationship between them. Therefore, Johansen test based on VAR model can be adopted. Considering the criteria of LR, FPE, AIC, HQ and SC, the optimal lag period is finally determined to be 3 . Then build VAR (3) model and the eigenvalues are all in the unit circle, which indicates that the model is stable.
According to VAR(3) model, make cointegration analysis and the results of the Johansen cointegration test are shown in Table 2. Both trace test and maximum eigenvalue test reject the original hypothesis of no cointegration at the $5 \%$ significance level, indicating that there is a cointegration relationship between iron ore futures prices and spot prices. It suggests that in the short term, the futures price and the spot price may deviate from the equilibrium, but there is a long-term equilibrium relationship between them.

TABLE II. JOHANSEN COINTEGRATION TEST

\begin{tabular}{|c|c|c|c|c|c|c|}
\hline \multirow{2}{*}{ Null Hypothesis } & \multirow{2}{*}{ Eigenvalue } & \multicolumn{2}{|l|}{ Trace Test } & \multicolumn{3}{|c|}{ Maximum Eigenvalue Test } \\
\hline & & Trace Statistics & Prob. & $\begin{array}{l}\text { Max-Eigen } \\
\text { Statistic }\end{array}$ & Prob. & \\
\hline No cointegration relationship & 0.034490 & 42.89258 & 0.0000 & 36.04685 & 0.0000 & \\
\hline $\begin{array}{lll}\text { At most } & 1 & \text { cointegration } \\
\text { relationship } & & \\
\end{array}$ & 0.006644 & 6.845726 & 0.0089 & 6.845726 & 0.0089 & \\
\hline \multicolumn{3}{|c|}{$\begin{array}{l}\text { D. Vector error correction model } \\
\text { In order to further study the short-term fluctuation between } \\
\text { iron ore futures price and spot price, it is necessary to establish } \\
\text { a vector error correction model. The error correction equations } \\
\text { for iron ore futures and spot prices are as following: }\end{array}$} & \multicolumn{3}{|c|}{$\begin{array}{l}d(\ln F)=-0.005 e c m_{t-1}+0.041 d(\ln F)_{t-1}-0.041 d(\ln F)_{t-2} \\
+0.523 d(\ln P)_{t-1}-0.148 d(\ln P)_{t-2} \\
d(\ln P)=0.041 e c m_{t-1}+0.037 d(\ln F)_{t-1}+0.004 d(\ln F)_{t-2} \\
+0.287 d(\ln P)_{t-1}-0.121 d(\ln P)_{t-2}\end{array}$} & (1) \\
\hline
\end{tabular}

In the above equations, ecm is an error correction term, standing for the long-term equilibrium relationship between the futures price and the spot price. The coefficient of $\mathrm{ecm}$ can 
reflect how long the relationship between the futures price and the spot price takes to adjust to the long-term equilibrium when it is at the state of short-term disequilibrium.

In (1), the coefficient of ecm is negative, while in (2), the coefficient of ecm is positive, indicating that there is a bi-directional equilibrium adjustment relationship between the futures price and the spot price. If the previous futures price is lower than the equilibrium price or the previous spot price is higher than the equilibrium price, ecm is less than 0 and $-0.005 \mathrm{ecm}$ produces a positive influence on the current futures price, which makes the current futures price rise to the long-term equilibrium, at the same time, $0.041 \mathrm{ecm}$ produces a negative influence on the current spot price, which makes the current spot price drop to the long-term equilibrium. If the previous futures price is higher than the equilibrium price or the previous spot price is lower than the equilibrium price ecm is greater than 0 and $-0.005 e \mathrm{~cm}$ produces a negative influence on current futures price, which makes the current futures price drop to the long-term equilibrium, at the same time, $0.041 \mathrm{ecm}$ produces a positive influence on the current spot price, which makes the current spot price rise to the long-term equilibrium.

The absolute value of the error correction coefficient in (1) is greater than that in (2), indicating that the futures price adjusts to the long-term equilibrium faster than the spot price. In other words, compared with the futures market, the spot market is more sensitive to the departure of short-term price from equilibrium, and adjusts to long-term equilibrium more quickly.

\section{E. Granger causality test}

Make Granger causality test to China's iron ore futures price and spot price. The results are shown in Table 3. At the $5 \%$ significance level, the spot price does Granger cause the futures price, but the futures price does not Granger cause the spot price. It means that the spot price unidirectionally guides the futures price, that is to say, the change of iron ore spot price has a obvious effect on futures price, while the change of iron ore futures price has little influence on spot price.

TABLE III. GRANGER CAUSALITY TEST

\begin{tabular}{|l|l|l|l|l|}
\hline Null Hypothesis & \multirow{2}{*}{ Lag } & F-Statistic & Prob. & Conclusion \\
\hline DLNP does not Granger Cause DLNF & \multirow{2}{*}{1} & 91.4223 & $8 . \mathrm{E}-21$ & reject \\
\cline { 5 - 6 } DLNF does not Granger Cause DLNP & & 0.92884 & 0.3354 & not reject \\
\hline DLNP does not Granger Cause DLNF & \multirow{2}{*}{100} & 2.04799 & $9.00 \mathrm{E}-08$ & reject \\
\cline { 5 - 6 } DLNF does not Granger Cause DLNP & & 1.09579 & 0.2575 & not reject \\
\hline
\end{tabular}

\section{F. Establishment of SVAR model}

The VAR model can not clearly show the current correlation between variables. In order to fully investigate the relationship between endogenous variables, it is necessary to establish a binary SVAR model to reflect the dynamic feedback process of interaction between iron ore futures markets and spot markets. In this paper, the AB-type SVAR model is selected. The variables are $\ln F$ and $\ln \mathrm{P}$ in turn, and five constraints are needed to identify the model. Assuming that the diagonal elements of A matrix are 1 and $\mathrm{B}$ matrix is a diagonal matrix, four constraints are imposed; thus, there is still one constraint required. As the iron ore spot price has a one-way guiding effect on the futures price, it can be assumed that the current impact of the futures price on the spot price is equal to 0 . According to the above conditions, A matrix and $\mathrm{B}$ matrix can be expressed as following:

$$
\mathrm{A}=\left[\begin{array}{cc}
1 & C(1) \\
0 & 1
\end{array}\right], \quad \mathrm{B}=\left[\begin{array}{cc}
C(2) & 0 \\
0 & C(3)
\end{array}\right]
$$

$\mathrm{C}(1), \mathrm{C}(2)$, and $\mathrm{C}(3)$ can be estimated by full-information maximum likelihood method and the estimated results are shown in Table 4 . It can be seen from Table 4 that the P-value of every coefficient is 0 , indicating that all coefficients are significant. The Log likelihood hood of the model is 5818.505, indicating that this model is ideal so that it is appropriate to make impulse response analysis.

TABLE IV. SVAR MODEL ESTIMATION RESULTS

\begin{tabular}{|l|l|l|l|l|}
\hline Parameter & Coefficient & Std. Error & z-Statistic & Prob. \\
\hline $\mathrm{C}(1)$ & -0.85235 & 0.030803 & -27.67136 & 0.0000 \\
\hline $\mathrm{C}(2)$ & 0.014148 & 0.000312 & 45.32108 & 0.0000 \\
\hline $\mathrm{C}(3)$ & 0.014332 & 0.000316 & 45.32108 & 0.0000 \\
\hline
\end{tabular}

G. Impulse response analysis

Based on SVAR (3) model, the impulse response function of China's iron ore futures price and spot price can be established. The results are shown in Figure 1.
Both the futures market and the spot market can respond positively to a structure shock from the spot market in the current period and then their extents of response increase rapidly until the second period when the futures market and the spot market both have strongest response. After the second 
period, the impact of the spot market gradually become weaker on the futures market and the spot market. Compare the two markets, the response intensity of the futures market to the spot market is slightly less than that of the spot market to its own shock.

The spot market has no response to a structure shock from the futures market in the current period, but then the impact of the futures market on the spot market gradually increases until the 48th period and 49th period when the impact is greatest,

\section{Response to Structural One S.D. Innovations}

Response of LNF to Shock1

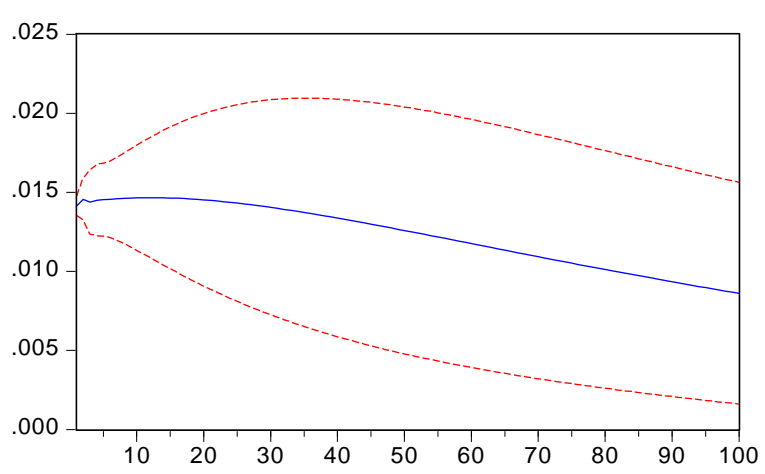

Response of LNP to Shock1

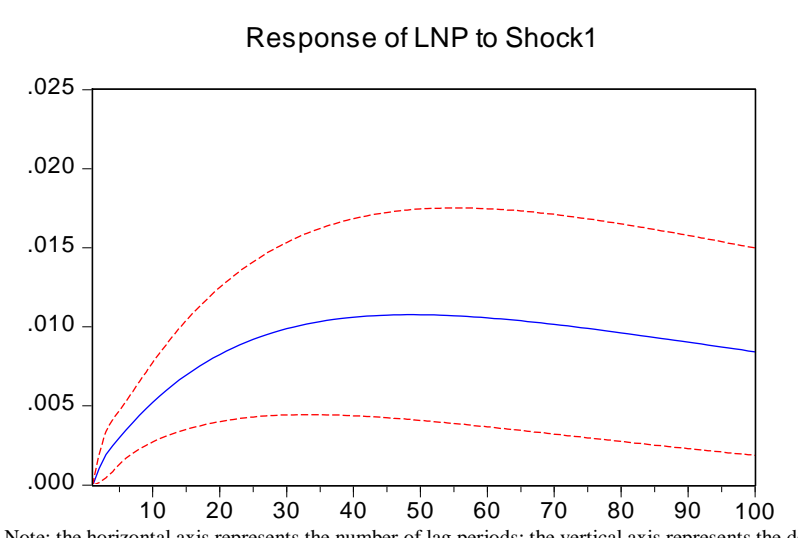

afterwards the impact is gradually weakened, which suggests that there is a significant lag in the spot market when it suffer a shock from the futures market. The futures market responds positively to a structural shock from itself in the current period, and the response intensity increases slightly in the second period, afterwards it stays at a stable level and then shows a slow downward trend from the 20th period. Generally speaking, the impact of iron ore futures market on the spot market is weaker than that of the spot market on the futures market.
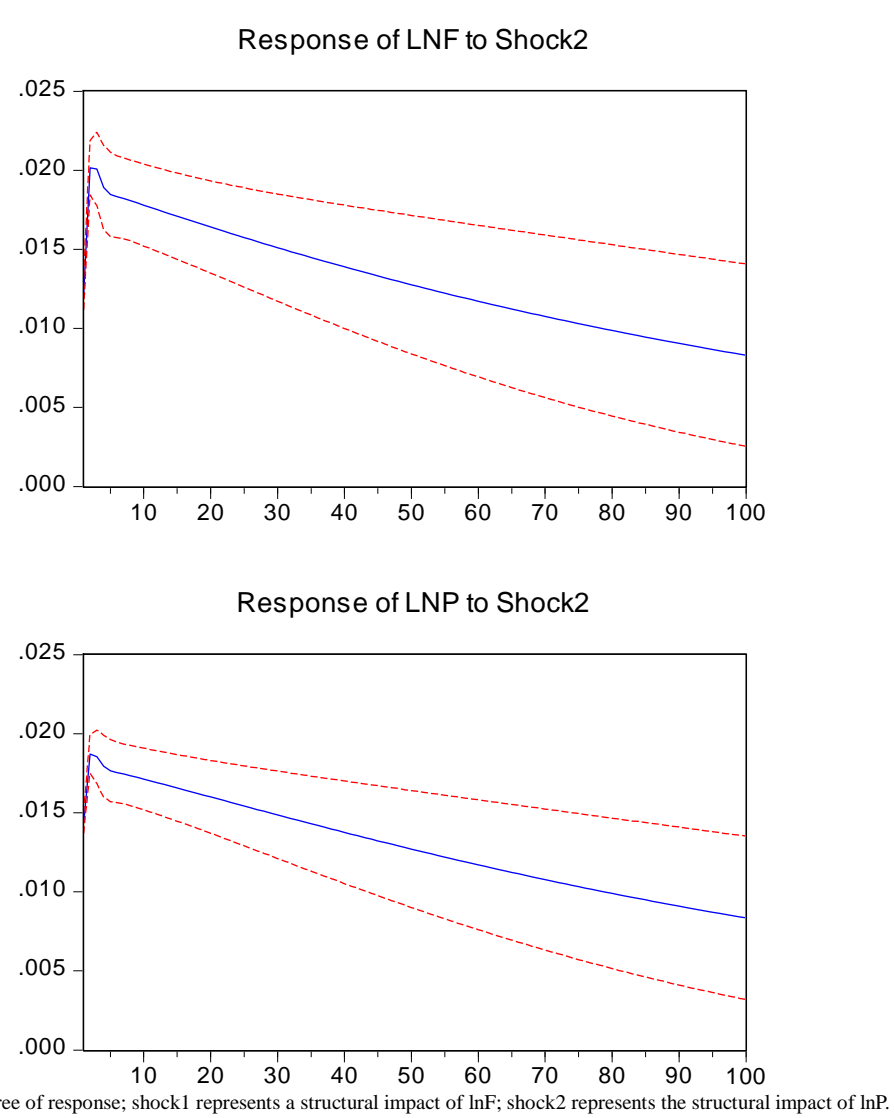

Fig. 1. Results of Impulse response

\section{CONCLUSION}

This paper makes a quantitative analysis of the relationship between China's iron ore futures markets and spot markets based on the relevant data of futures price and spot price, and then draws the following conclusions:

Firstly, there is a long-term equilibrium relationship between China's iron ore futures price and spot price, indicating that China's iron ore futures market has initially possessed the function of risk aversion, thus market participants can hedge with iron ore futures to effectively reduce price risk. In the short run, when the relationship between futures price and spot price deviates from long-term equilibrium, the spot price adjusts to long run equilibrium more quickly than the futures price.

Secondly, China's iron ore spot price unidirectionally guides the futures price, suggesting that the futures market does not have a complete function of price discovery. Iron ore spot market has a greater impact on the futures market, while the impact of the futures market on the spot market is smaller, indicating that the iron ore futures market does not work in an efficient way. The main reason is that China have little pricing power for iron ore.

At present, China has become the largest iron ore spot market in the world, and it is in urgent need of international futures market to be matched with. Therefore, it is important to actively explore the innovation of iron ore futures contract system, strengthen the construction of over-the-counter market, further enrich the structure of iron ore derivatives and reduce the operating costs of the market to improve the efficiency of the futures market. 


\section{REFERENCES}

[1] Engle R F, Granger C W J. Co-integration and error correction: representation, estimation, and testing[J]. Econometrica, 1987, 55(2): 251-76.

[2] Lai k, Lai M. A cointegration test for market efficiency[J]. Journal of Futures Markets, 1991, (11): 567- 575.

[3] Booth G G, So R W, Tse Y. Price discovery in the German equity index derivatives markets [J]. Journal of Futures Markets, 1999, 19(6): 619-643.

[4] Sun Xinxin. The dynamic relationship between CSI 300 and CSI 300 index futures-a perspective based on intraday high-frequency data in Shanghai and Shenzhen stock market[J]. Shanghai Journal of Economics, 2018(05): 81-92. (In Chinese)

[5] Song Bo, Deng Ying. Price discovery and price feedback of grain future and spot markets of China[J]. Prices Monthly, 2018(06): 23-29. (In Chinese)

[6] Dong Shanshan, Feng Yun, Du Wei. Research on price discovery function of precious metal futures market in China[J]. Price: Theory \& Practice, 2016(02): 128-130. (In Chinese) 